\title{
Drexel University Temperature Sensors
}

\author{
K. L. Davis \\ D. L. Knudson \\ J. L. Rempe \\ B. M. Chase
}

September 22, 2014

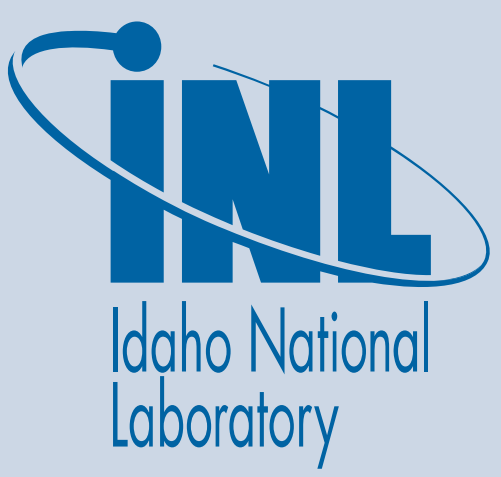




\section{DISCLAIMER}

This information was prepared as an account of work sponsored by an agency of the U.S. Government. Neither the U.S. Government nor any agency thereof, nor any of their employees, makes any warranty, express or implied, or assumes any legal liability or responsibility for the accuracy, completeness, or usefulness of any information, apparatus, product, or process disclosed, or represents that its use would not infringe privately owned rights. References herein to any specific commercial product, process, or service by trade name, trademark, manufacturer, or otherwise, does not necessarily constitute or imply its endorsement, recommendation, or favoring by the U.S. Government or any agency thereof. The views and opinions of authors expressed herein do not necessarily state or reflect those of the U.S. Government or any agency thereof. 
INL/EXT-14-33067

\title{
Drexel University Temperature Sensors
}

\author{
K. L. Davis \\ D. L. Knudson \\ J. L. Rempe \\ B. M. Chase
}

September 22, 2014

\author{
Idaho National Laboratory \\ Idaho Falls, Idaho 83415 \\ Prepared for the \\ U.S. Department of Energy \\ Office of Nuclear Energy, Science, and Technology \\ Under DOE Idaho Operations Office \\ Contract DE-AC07-05ID14517
}





\section{Drexel University Temperature Sensors}

\section{Introduction}

This document summarizes background information and presents results related to temperature measurements in the Advanced Test Reactor (ATR) National Scientific User Facility (NSUF) Drexel University Project 31091 irradiation. As documented in Reference 1, the objective of this test was to assess the radiation performance of new ceramic materials for advanced reactor applications. Accordingly, irradiations of transition metal carbides and nitrides were performed using the Hydraulic Shuttle Irradiation System (HSIS) in the B-7 position and in static capsules inserted into the A-3 and East Flux Trap Position 5 locations of the ATR.

Only the HSIS capsules contained temperature sensors, consisting of quartz-encapsulated melt wire assemblies and Silicon Carbide ( $\mathrm{SiC}$ ) temperature monitors. A total of six HSIS titanium capsules were included in the test, and the capsules were irradiated for approximately 10 Effective Full Power Days (EFPDs) to a maximum fluence of $7 \times 10^{19} \mathrm{n} / \mathrm{cm}^{2}(\mathrm{E}>1 \mathrm{MeV})$. Pre-test thermal and physics analyses ${ }^{2,3}$ indicate that two capsules would be irradiated at $110^{\circ} \mathrm{C}$ (with the $\mathrm{SiC}$ monitors receiving a 0.1 dpa dose); two capsules would be irradiated at $725^{\circ} \mathrm{C}$ (with the $\mathrm{SiC}$ monitors receiving a $0.1 \mathrm{dpa}$ dose); and two capsules would be irradiated at $1100^{\circ} \mathrm{C}$ (with the $\mathrm{SiC}$ monitors receiving a $0.1 \mathrm{dpa}$ dose). Figure 1 shows the design of the HSIS capsule with the location of a melt wire assembly (containing four melt wires) and the location of an $\mathrm{SiC}$ monitor. Figure 2 shows a radiograph of one of the capsules prior to irradiation.

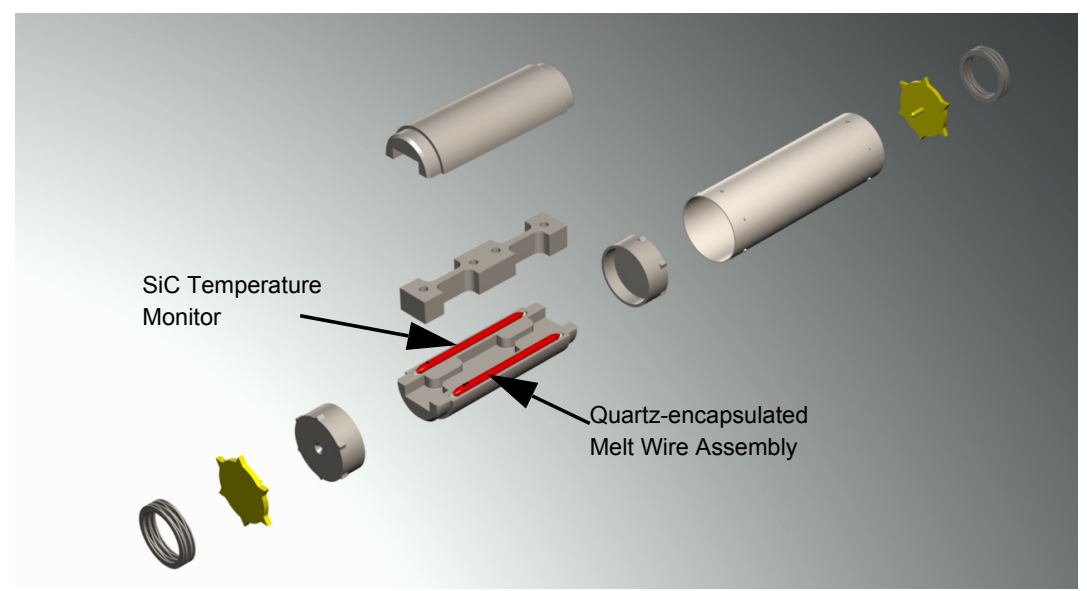

Figure 1. Drexel University HSIS capsule design.

This report documents results from an evaluation of the temperature sensors for two of the six HSIS capsules. One of the evaluated capsules (with a predicted irradiation temperature of $110^{\circ} \mathrm{C}$ ) will be identified as KGT-1368, while the other evaluated capsule (with a predicted irradiation temperature of $725^{\circ} \mathrm{C}$ ) will be identified as KGT-1370. (Capsules with predicted irradiation temperatures of $1100{ }^{\circ} \mathrm{C}$ were not evaluated because $\mathrm{SiC}$ has not been shown to be a reliable monitor if irradiated above the recrystallization temperature, e.g., above $800{ }^{\circ} \mathrm{C}$.) It is critical to note that the KGT-1368 predicted irradiation temperature and dose and the KGT-1370 dose are below the recommended range for SiC temperature monitor use (see Section 3). Consequently, uncertainties in this evaluation cannot be readily quantified. 


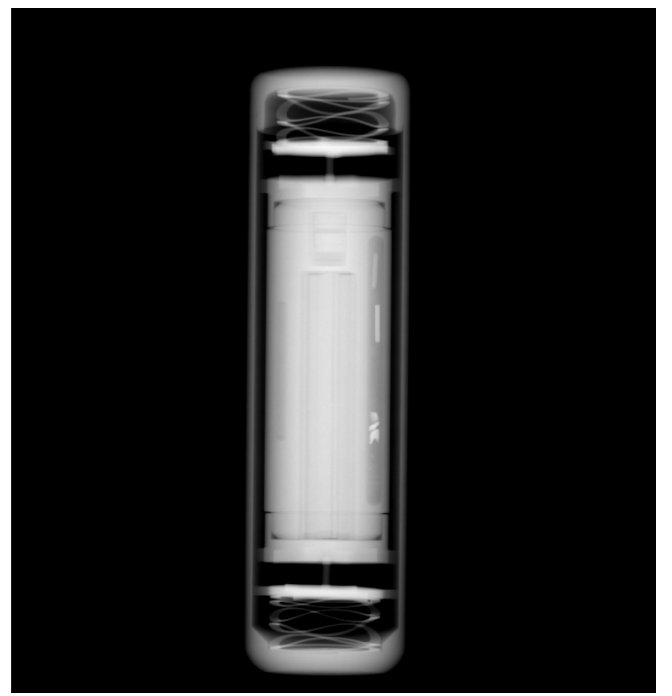

Figure 2. Radiograph of typical Drexel University capsule prior to irradiation.

\section{Melt Wire Temperature Sensors}

An evaluation of the melt wire assemblies was undertaken to validate temperature predictions from the pretest thermal and reactor physics analyses. Insights from melt wire evaluations can be used to select appropriate temperatures for more efficient $\mathrm{SiC}$ temperature monitor evaluations.

\subsection{Selection and Prior Experience with Selected Wires}

The melt wires listed in Table 1 were selected to bound estimated temperatures for the Drexel test. These materials were selected from a library of melt wire materials maintained by Idaho National Laboratory's (INL's) High Temperature Test Laboratory (HTTL). Many of the wires included in this test had their melting temperature evaluated using an HTTL differential scanning calorimeter (DSC). ${ }^{4,5}$ In addition, HTTL furnace tests of quartz encapsulated tubes containing materials from the HTTL melt wire library provide insights related to the ability to visually discern melting after heating to temperatures above melting. ${ }^{6,7}$ These insights are summarized in column 3 of Table 1.

Table 1. Summary of melt wires included in Drexel University test.

\begin{tabular}{|c|c|c|}
\hline $\begin{array}{l}\text { Melt Wire } \\
\text { Material }^{\mathrm{a}}\end{array}$ & $\begin{array}{l}\text { Melt Temperature } \\
\left({ }^{\circ} \mathrm{C}\right)\end{array}$ & Comment \\
\hline \multicolumn{3}{|r|}{$110^{\circ} \mathrm{C}$ Capsules } \\
\hline $\begin{array}{l}56.2 \mathrm{Bi} 33.8 \mathrm{~Pb} \\
10 \mathrm{Sn}\end{array}$ & 85.0 & $\begin{array}{l}\text { HTTL Evaluated (TEV-1175); furnace tests indicate morphology } \\
\text { changes by } 105^{\circ} \mathrm{C} \text {. }\end{array}$ \\
\hline $65 \mathrm{Bi} 35 \mathrm{In}$ & 110.6 & $\begin{array}{l}\text { HTTL Evaluated (TEV-1175); furnace tests indicate discoloration and } \\
\text { morphology changes by } 117^{\circ} \mathrm{C} \text {. }\end{array}$ \\
\hline $55.2 \mathrm{Bi} 44.8 \mathrm{~Pb}$ & 126.4 & $\begin{array}{l}\text { HTTL Evaluated (TEV-1175); furnace tests indicate discoloration and } \\
\text { morphology changes by } 130{ }^{\circ} \mathrm{C} \text {. }\end{array}$ \\
\hline $57 \mathrm{Bi} 43 \mathrm{Sn}$ & 139.4 & $\begin{array}{l}\text { HTTL Evaluated (TEV-1175); furnace tests indicate discoloration and } \\
\text { morphology changes by } 145^{\circ} \mathrm{C} \text {. }\end{array}$ \\
\hline \multicolumn{3}{|r|}{$725^{\circ} \mathrm{C}$ Capsules } \\
\hline $\mathrm{Zn}$ & 419.3 & $\begin{array}{l}\text { HTTL evaluated (TEV-1141); Furnace tests difficult to interpret (some } \\
\text { discoloration occurs in some tests after } 335^{\circ} \mathrm{C} \text {; slight surface changes at } \\
430^{\circ} \mathrm{C} \text { may indicate melt). }\end{array}$ \\
\hline
\end{tabular}


Table 1. Summary of melt wires included in Drexel University test. (continued)

\begin{tabular}{|c|c|c|}
\hline $\begin{array}{l}\text { Melt Wire } \\
\text { Material }^{\text {a }}\end{array}$ & $\begin{array}{l}\text { Melt Temperature } \\
\left({ }^{\circ} \mathrm{C}\right)\end{array}$ & Comment \\
\hline $80 \mathrm{Sb} 20 \mathrm{Zn}$ & 507.8 & $\begin{array}{l}\text { HTTL evaluated (TEV-1175); Chards; Furnace tests indicate melting not } \\
\text { until } 520 \text { to } 540^{\circ} \mathrm{C} \text {; oxidation may have caused discrepancy. }\end{array}$ \\
\hline $\mathrm{Al}$ & 660.5 & $\begin{array}{l}\text { Furnace test results varied; Some results indicate discoloration and } \\
\text { morphology observed by } 670^{\circ} \mathrm{C} \text { and melting by } 710^{\circ} \mathrm{C} \text {. }\end{array}$ \\
\hline $\begin{array}{l}49 \mathrm{Ag} 16 \mathrm{Cu} 23 \mathrm{Zn} \\
7.5 \mathrm{Mn} 4.5 \mathrm{Ni}\end{array}$ & 681.3 & HTTL Evaluated (TEV-1175). \\
\hline \multicolumn{3}{|r|}{$1100^{\circ} \mathrm{C}$ Capsule - Side A } \\
\hline $1.8 \mathrm{Be} 98.2 \mathrm{Cu}$ & 865.1 & $\begin{array}{l}\text { HTTL Evaluated (TEV-1175); furnace tests indicate discoloration } \\
850^{\circ} \mathrm{C} \text { and morphology changes by } 890^{\circ} \mathrm{C} \text {. }\end{array}$ \\
\hline$\overline{\mathrm{Ag}}$ & 962.0 & Phase diagram; Furnace tests indicate melting above $985^{\circ} \mathrm{C}$. \\
\hline $65 \mathrm{Cu} 35 \mathrm{Au}$ & 995.6 & $\begin{array}{l}\text { HTTL Evaluated (TEV-1175); DSC results indicate melting easy to } \\
\text { observe, but only morphology changes in furnace test above } 1030^{\circ} \mathrm{C} \text {. }\end{array}$ \\
\hline $\mathrm{Cu}$ & 1083 & $\begin{array}{l}\text { Phase diagram. Only morphology changes in furnace tests above } \\
1100^{\circ} \mathrm{C} \text {. }\end{array}$ \\
\hline \multicolumn{3}{|r|}{$1100^{\circ} \mathrm{C}$ Capsule - Side B } \\
\hline $1.8 \mathrm{Be} 98.2 \mathrm{Cu}$ & 865.1 & $\begin{array}{l}\text { HTTL Evaluated (TEV-1175); furnace tests indicate discoloration } \\
850^{\circ} \mathrm{C} \text { and morphology changes by } 890^{\circ} \mathrm{C} \text {. }\end{array}$ \\
\hline $70 \mathrm{Cu} 30 \mathrm{Ni}$ & 1191.0 & $\begin{array}{l}\text { HTTL Evaluated (TEV-1175); furnace tests indicate discoloration and } \\
\text { morphology changes by } 985^{\circ} \mathrm{C} \text {. }\end{array}$ \\
\hline $\mathrm{Ag}$ & 962.0 & Phase diagram. Furnace tests indicate melting above $985^{\circ} \mathrm{C}$. \\
\hline $\mathrm{Au}$ & 1064 & Phase diagram. Furnace tests indicate melting above $1075^{\circ} \mathrm{C}$. \\
\hline
\end{tabular}

a. Listed with weight percent of each element.

\subsection{Initial Melt Wire Results}

Post irradiation evaluations indicate that none of the quartz tubes experienced any darkening. The state of the wires was easily observed, but not easily photographed. Preliminary results are summarized in this section with recommendations for $\mathrm{SiC}$ temperature monitor evaluations.

\subsection{1. $110{ }^{\circ} \mathrm{C}$ Results}

Post-irradiation photos of KGT-1368 are too far out of focus to determine if any of the wire samples melted as indicated in Figure 3.
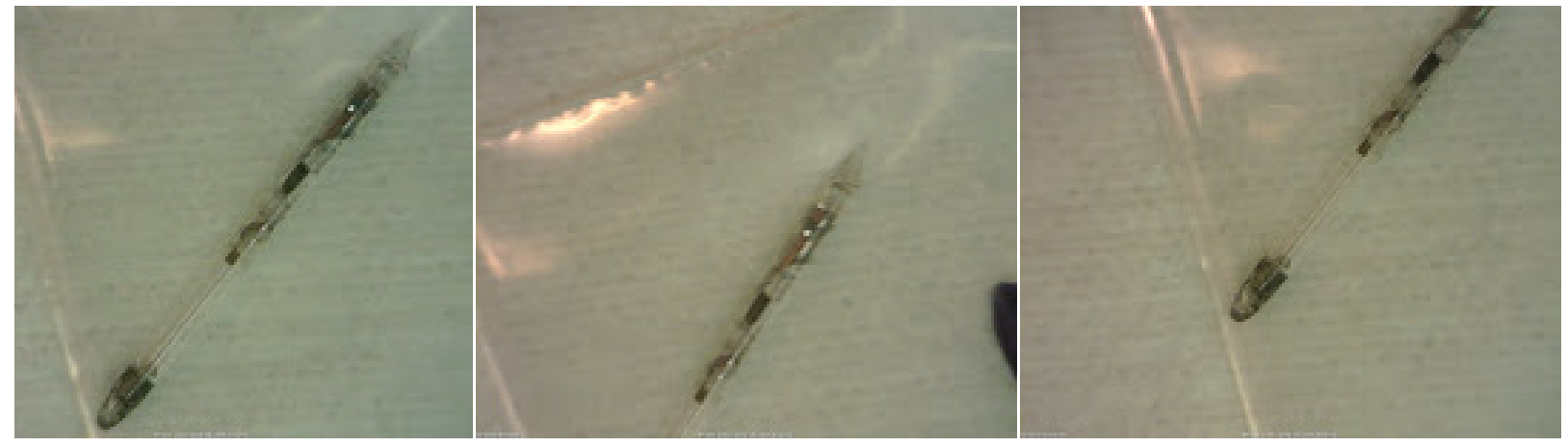

Figure 3. KGT-1368 (higher melting point material, $57 \mathrm{Bi} 43 \mathrm{Sn}$, near painted end). 


\subsection{2. $725^{\circ} \mathrm{C}$ Results}

The quartz tube broke during disassembly. These photos are unclear, and it is unknown which melt wire materials remain in the tube fragment shown in Figure 4.
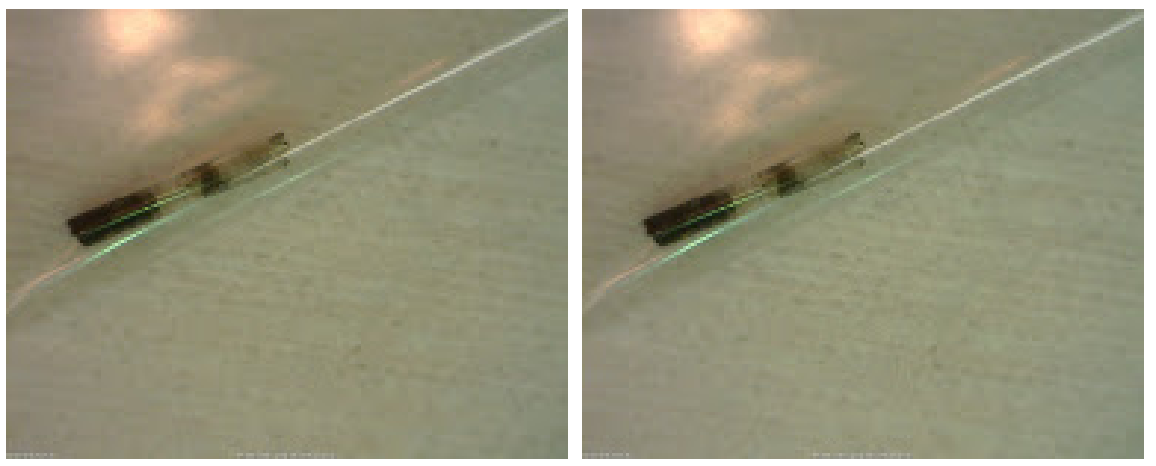

Figure 4. KGT-1370 (higher melting point material, $49 \mathrm{Ag} 16 \mathrm{Cu} 23 \mathrm{Zn} 7.5 \mathrm{Mn} 4.5 \mathrm{Ni}$, near painted end, but painted end not evident in fragment).

\subsubsection{Conclusions and Recommendations for SiC Evaluations}

Results presented in this section indicate that melt wire evaluation results are inconclusive. Table 2 summarizes recommendations for $\mathrm{SiC}$ monitor evaluations based on pre-test thermal analysis results.

Table 2. Preliminary melt wire evaluation for the Drexel University test.

\begin{tabular}{|c|c|}
\hline Capsule & Comment and Recommendation \\
\hline & $110^{\circ} \mathrm{C}$ Capsule ${ }^{\mathrm{a}}$ \\
\hline \multirow[t]{2}{*}{ KGT-1368 } & Photos too far out of focus for any conclusions. \\
\hline & $\begin{array}{l}\text { Recommendation for } \mathrm{SiC} \text { Monitor Evaluations: Start } \mathrm{SiC} \text { monitor evaluation at } 40^{\circ} \mathrm{C} \text {, } \\
\text { increment to the anneal temperatures of } 50,60,80 \text { and } 100^{\circ} \mathrm{C} \text {, then increase the anneal } \\
\text { temperature for subsequent data points by } 10^{\circ} \mathrm{C} \text { until a change in resistivity is observed. }\end{array}$ \\
\hline \multicolumn{2}{|r|}{$725^{\circ} \mathrm{C}$ Capsules ${ }^{b}$} \\
\hline \multirow[t]{2}{*}{ KGT-1370 } & Photos too far out of focus for any conclusions. \\
\hline & $\begin{array}{l}\text { Recommendation for } \mathrm{SiC} \text { Monitor Evaluations: Start } \mathrm{SiC} \text { monitor evaluations at } 40^{\circ} \mathrm{C} \text {, } \\
\text { increment to the anneal temperature of } 50^{\circ} \mathrm{C} \text {, increase the anneal temperature for } \\
\text { subsequent data points by } 50^{\circ} \mathrm{C} \text { and take measurements up to } 6500^{\circ} \mathrm{C} \text {, then increase the } \\
\text { anneal temperature for subsequent data points by } 10^{\circ} \mathrm{C} \text { increments until a change in } \\
\text { resistivity is observed. }\end{array}$ \\
\hline
\end{tabular}

a. Estimated irradiation temperature and dose are lower than recommended ranges for SiC monitor use (see Section 3).

b. Estimated dose is lower than the recommended range for SiC monitor use (see Section 3).

\section{SiC Temperature Monitors}

As discussed in Section 1, SiC temperature monitors were incorporated into Drexel test capsules at the locations illustrated in Figures 1 and 2. (Note that these monitors were a fully dense chemical vapor deposition of silicon carbide procured from Dow Chemical Company. ${ }^{\mathrm{a}}$ ) Results from thermal analyses of the SiC monitors inserted in capsules designated KGT-1368 and KGT-1370 are reported in Table 3.

a. Purchased under Idaho National Laboratory quality assurance identifier QA165156. 
Table 3. Estimated temperatures for SiC monitors.

\begin{tabular}{|c|c|}
\hline Monitor Identification & Thermal Analysis Predictions $\left({ }^{\circ} \mathrm{C}\right)$ \\
\hline KGT-1368 & 110 \\
\hline KGT-1370 & 725 \\
\hline
\end{tabular}

\subsection{Background}

$\mathrm{SiC}$ has been used as a post-irradiation monitor to infer peak irradiation temperature since the early 1960s. As noted in Reference 8, several researchers have observed that neutron irradiation induced lattice expansion of $\mathrm{SiC}$ anneals out when the post-irradiation annealing temperature exceeds the irradiation temperature. More recent evaluations ${ }^{8-10}$ infer peak irradiation temperatures using changes in electrical resistivity because of improved accuracy, ease of measurement, and reduced costs of the experimental setup. Comparisons of temperatures inferred from $\mathrm{SiC}$ measurements and thermocouple data indicate that accuracies of approximately $20^{\circ} \mathrm{C}$ are possible for dose ranges of 1 to $8 \mathrm{dpa}$ and temperatures from 200 to at least $800^{\circ} \mathrm{C}$.

There are several limitations associated with the use of $\mathrm{SiC}$ temperature monitors. The use of $\mathrm{SiC}$ as a temperature monitor is intended for constant temperature irradiations. Reference 9 cites several specific examples where temperature variations during irradiation can introduce uncertainty in the $\mathrm{SiC}$ monitor measurements including:

- Irradiation temperatures rising during the latter part of irradiation. SiC swelling saturates at low fluence. For damages greater than $0.1 \mathrm{dpa}$, the increasing temperature will anneal out defects that occur at the lower irradiation temperature, while creating stable defects at the higher temperature. When isochronal annealing is performed, lower temperature defects are removed; and the recovery curve will be smeared to somewhat higher temperatures. If the temperature increase during irradiation is not great, or the time at higher temperature not too long, then the original departure from linearity will still give the earlier irradiation temperature.

- Irradiation temperatures decreasing during irradiation. This decrease will lead to defects being created and frozen-in at the higher-temperature, while continuing to create lower temperature defects. The isochronal anneal will then give an indication of the lowest irradiation temperature (in this case at the end of the irradiation period), and the recovery curve will be smeared because it will continue to anneal higher and higher temperature stable defects.

- Upward or downward temperature spikes during irradiation. Depending on the time at temperature, the effect will be to smear the recovery curve.

However, if irradiation tests are conducted at or near a constant temperature when the reactor is at power, none of these situations are of concern.

In addition, there are other sources of uncertainty that one should consider when comparing results from $\mathrm{SiC}$ temperature monitors and analysis predictions for peak temperatures. For example, Reference 8 provides information regarding the influence manufacturing tolerances of gas gaps can have on temperature control in irradiation tests. Thermal analysis of prior tests have been shown to have errors of up to $100{ }^{\circ} \mathrm{C}$ in tests conducted at $1400^{\circ} \mathrm{C}$. 


\subsection{Experimental Setup}

Electrical resistivity measurements were used to infer the peak irradiation temperature of the Drexel SiC monitors. Figure 5 depicts the equipment at the HTTL used to evaluate $\mathrm{SiC}$ monitors. The SiC monitors were heated isochronally in the annealing furnace. Based on the experiment analysis, the annealing temperatures were selected as specified in Section 2.2.3. The annealing furnace is located under a ventilation hood within a stainless steel enclosure. Annealing temperatures are recorded using a National Institute Standards and Technology (NIST) traceable, calibrated thermocouple inserted into an alumina tube in the furnace. After each isochronal annealing, the specimens are placed in a specialized fixture designed to take resistance measurements and inserted into a constant temperature chamber, normally maintained at $40{ }^{\circ} \mathrm{C}$, for a minimum of 30 minutes. After the sensor has equilibrated with the temperature in the chamber for at least 30 minutes, the resistance is measured using the specialized fixture which is connected to a calibrated DC power analyzer.

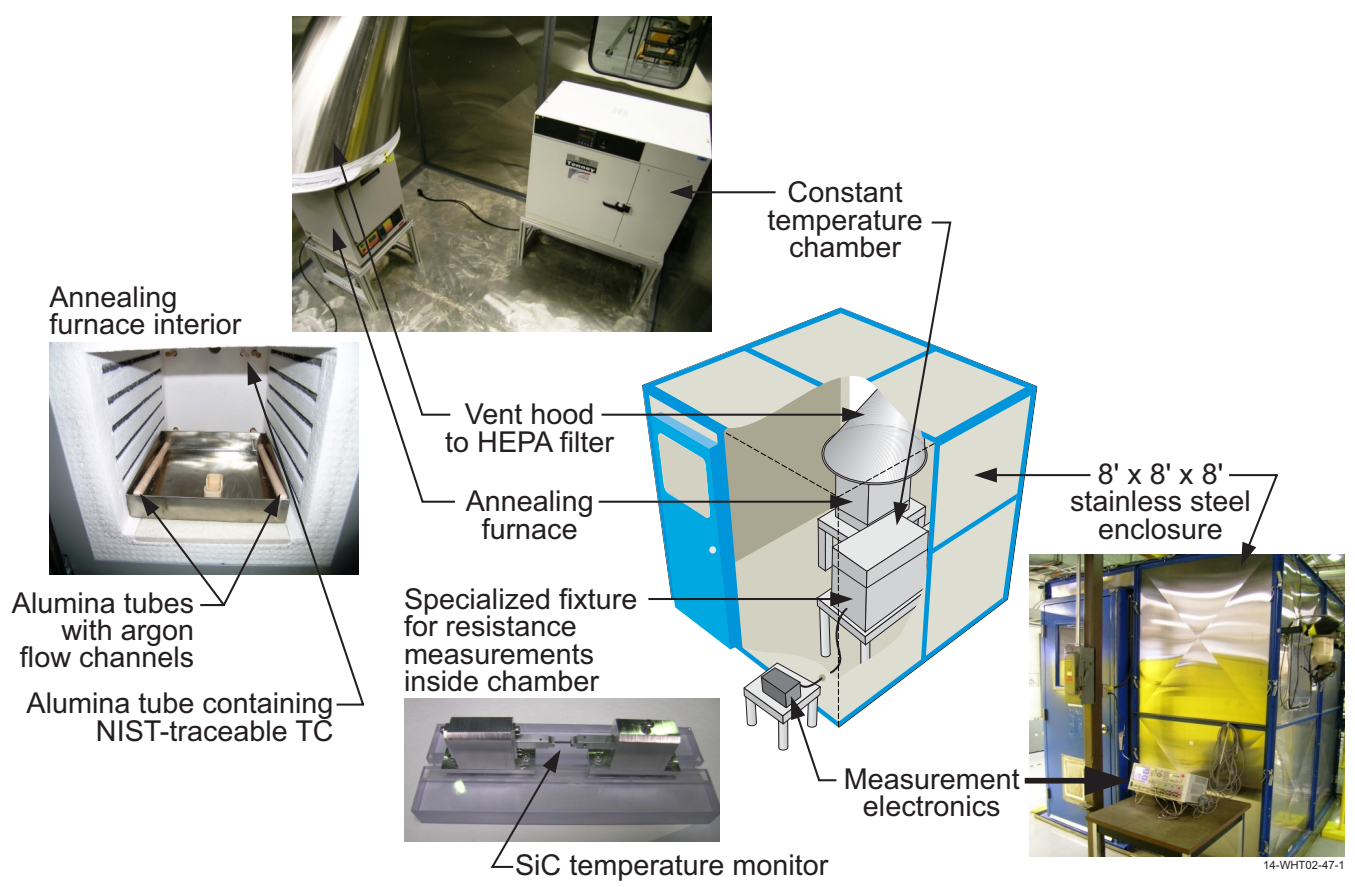

Figure 5. SiC equipment setup.

Initial resistance measurements of the $\mathrm{SiC}$ monitors are performed to determine the power analyzer settings to use for each post-anneal measurement. The ohmic response is used to ensure resistance heating in the sample is minimized and the current signal is stable for the given voltage. Figures 6 and 7 contain plots of the ohmic response for the KGT-1368 monitor and the KGT-1370 monitor, respectively. Based on those plots, an applied voltage of $4 \mathrm{~V}$ was selected for KGT-1368 to minimize resistance heating and $45 \mathrm{~V}$ was selected for KGT-1370 to yield a working current within the operating band of the DC analyzer.

\subsection{Results}

In comparing information in Table 3 and in Section 3.1, it may be observed that irradiation temperatures for one of the $\mathrm{SiC}$ monitors and dose ranges for all of the monitors included in the Drexel tests were not in the accepted ranges for their use (e.g., 200 to $800^{\circ} \mathrm{C}$ and 1 to $8 \mathrm{dpa}$ ). Nevertheless, evaluations were performed to gain insights about their use in lower temperature/lower dose ranges. 


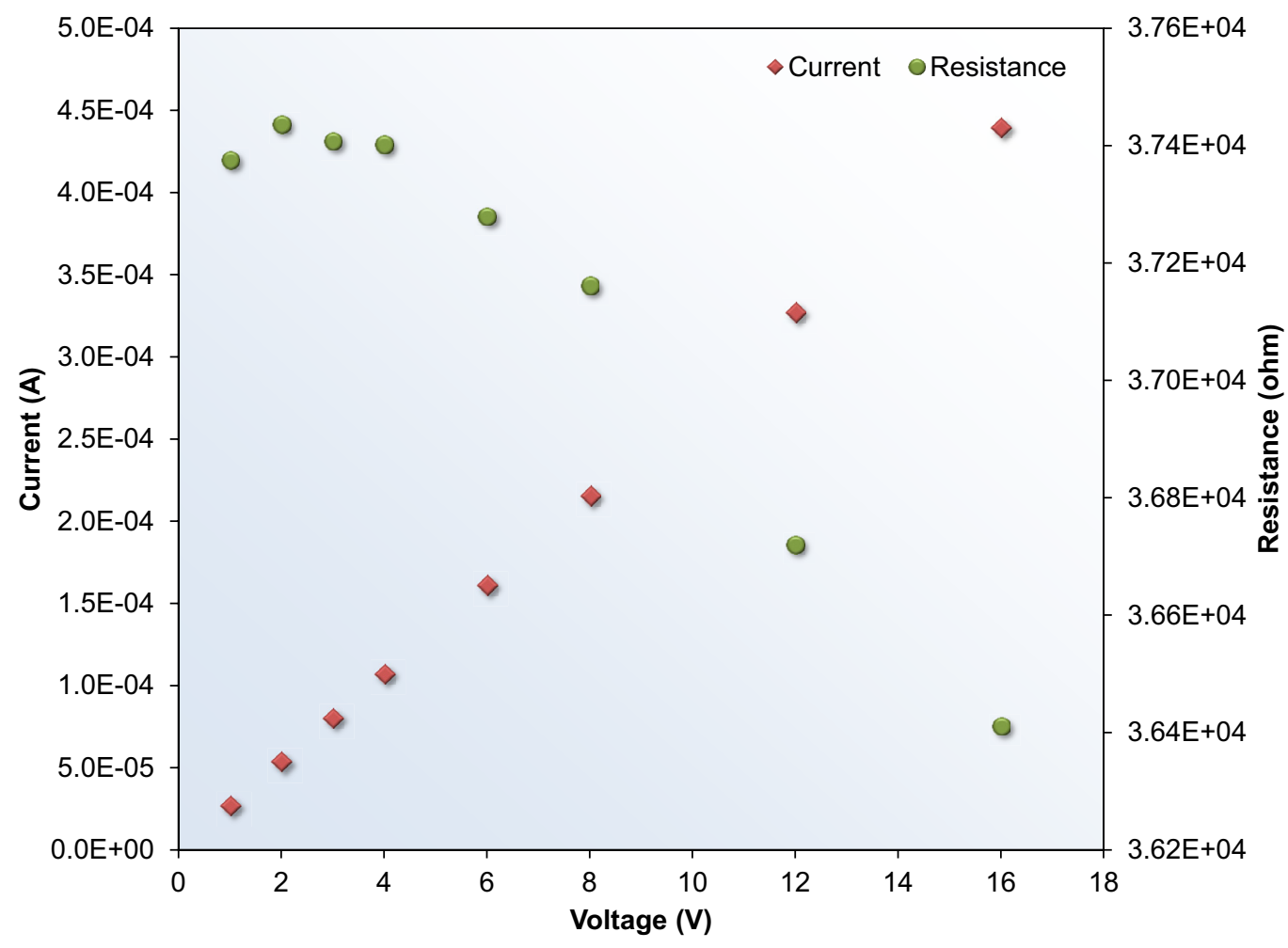

Figure 6. KGT-1368 ohmic response.

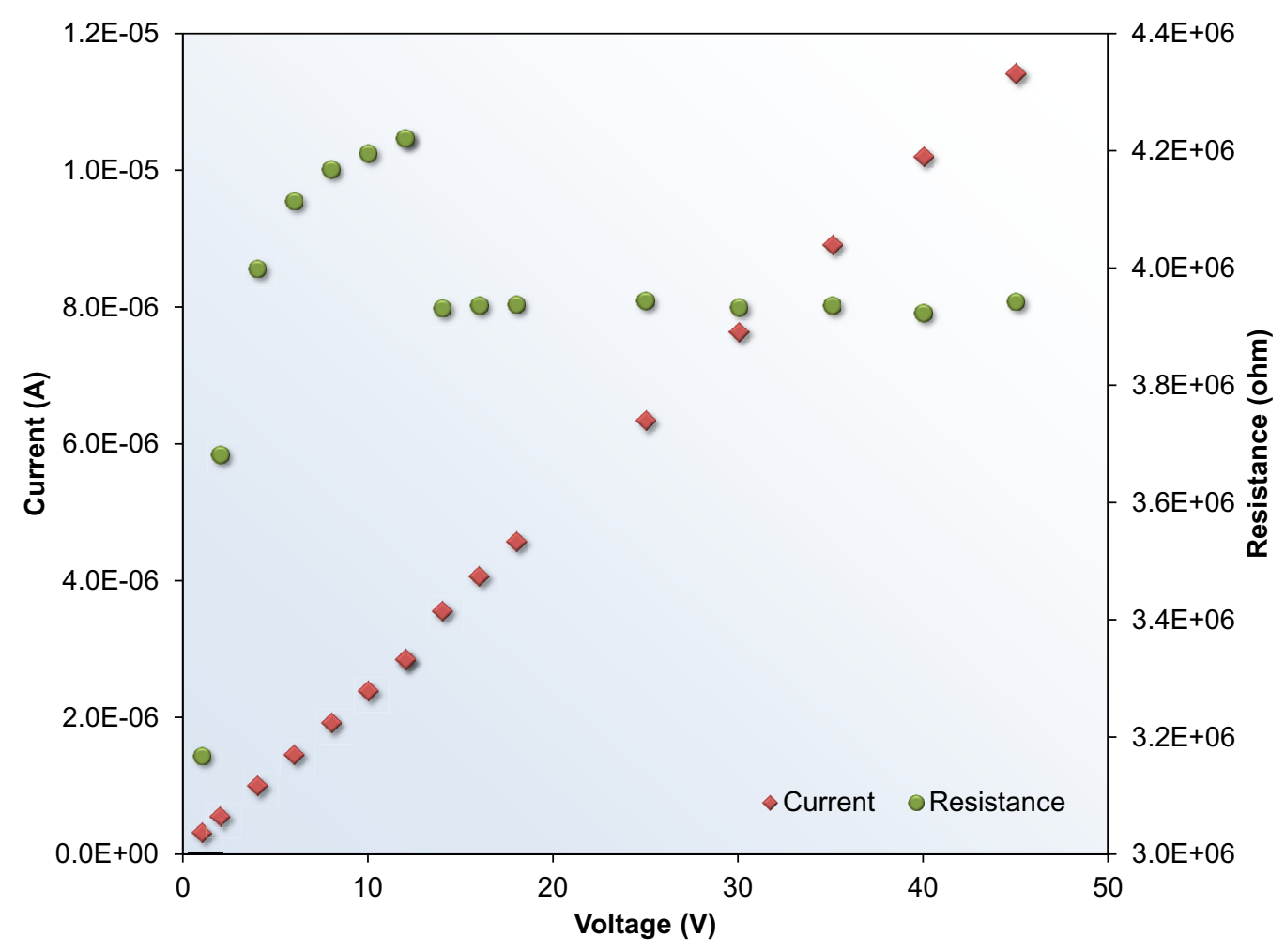

Figure 7. KGT-1370 ohmic response. 


\subsubsection{KGT-1368 Monitor}

Figure 8 is a plot of the resistivity data for the KGT-1368 monitor. As indicated in the figure, resistivity data show more or less random scattering with no clear upward as annealing temperatures were increased. Therefore, a peak irradiation temperature based on the resistivity data was indeterminate. This result may be expected given that the predicted irradiation temperature (of $110^{\circ} \mathrm{C}$ ) and the planned dose for this monitor (of $0.1 \mathrm{dpa}$ ) were below recommended ranges of 200 to $800^{\circ} \mathrm{C}$ and 1 to $8 \mathrm{dpa}$, respectively. Because there were no signs of a clear upward trend in resistivity, this evaluation was truncated at a final annealing temperature of $200{ }^{\circ} \mathrm{C}$.

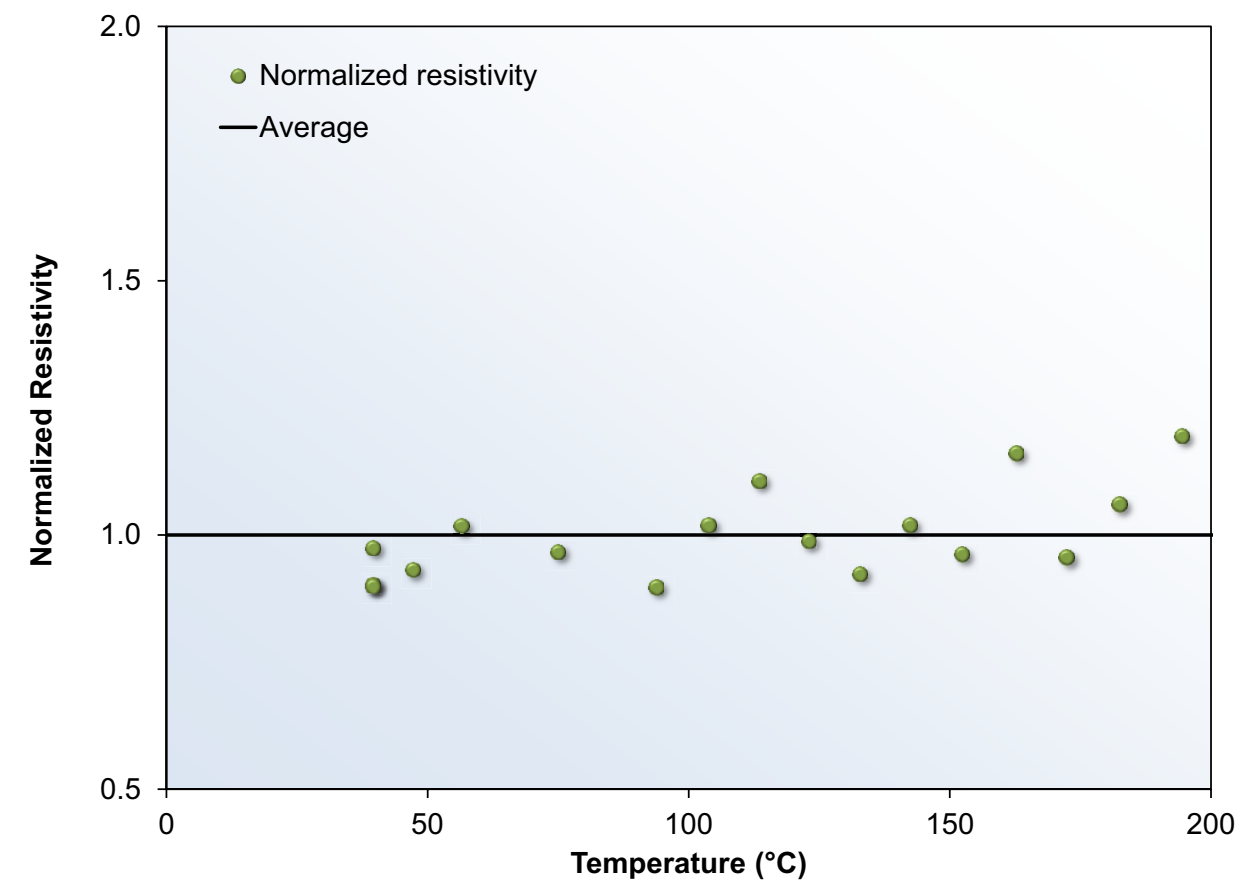

Figure 8. Resistivity data for KGT-1368 monitor.

\subsubsection{KGT-1370 Monitor}

Figure 9 is a plot of the resistivity data for the KGT-1370 monitor. As indicated in the figure, resistivity data show more or less random scattering with no clear upward as annealing temperatures were increased (similar to the results for the KGT-1368 monitor). Therefore, a peak irradiation temperature based on the resistivity data was indeterminate. This result may be expected given that the planned dose for this monitor (of $0.1 \mathrm{dpa}$ ) was below the recommended range of 1 to $8 \mathrm{dpa}$. Because there were no signs of a clear upward trend in resistivity, this evaluation was truncated at a final annealing temperature of $750{ }^{\circ} \mathrm{C}$.

\subsubsection{SiC Monitor Evaluations Summary}

SiC monitors, identified as KGT-1368 and KGT-1370, were evaluated to infer peak irradiation temperatures during the ATR NSUF Drexel University Project 31091 irradiation. Peak irradiation temperatures inferred from evaluation of KGT-1368 and KGT-1370 were indeterminate, as summarized in Table 4. A primary factor contributing to the poor response of these $\mathrm{SiC}$ is believed to be the fact that the SiC monitors were used outside the recommended temperature and dose ranges. 


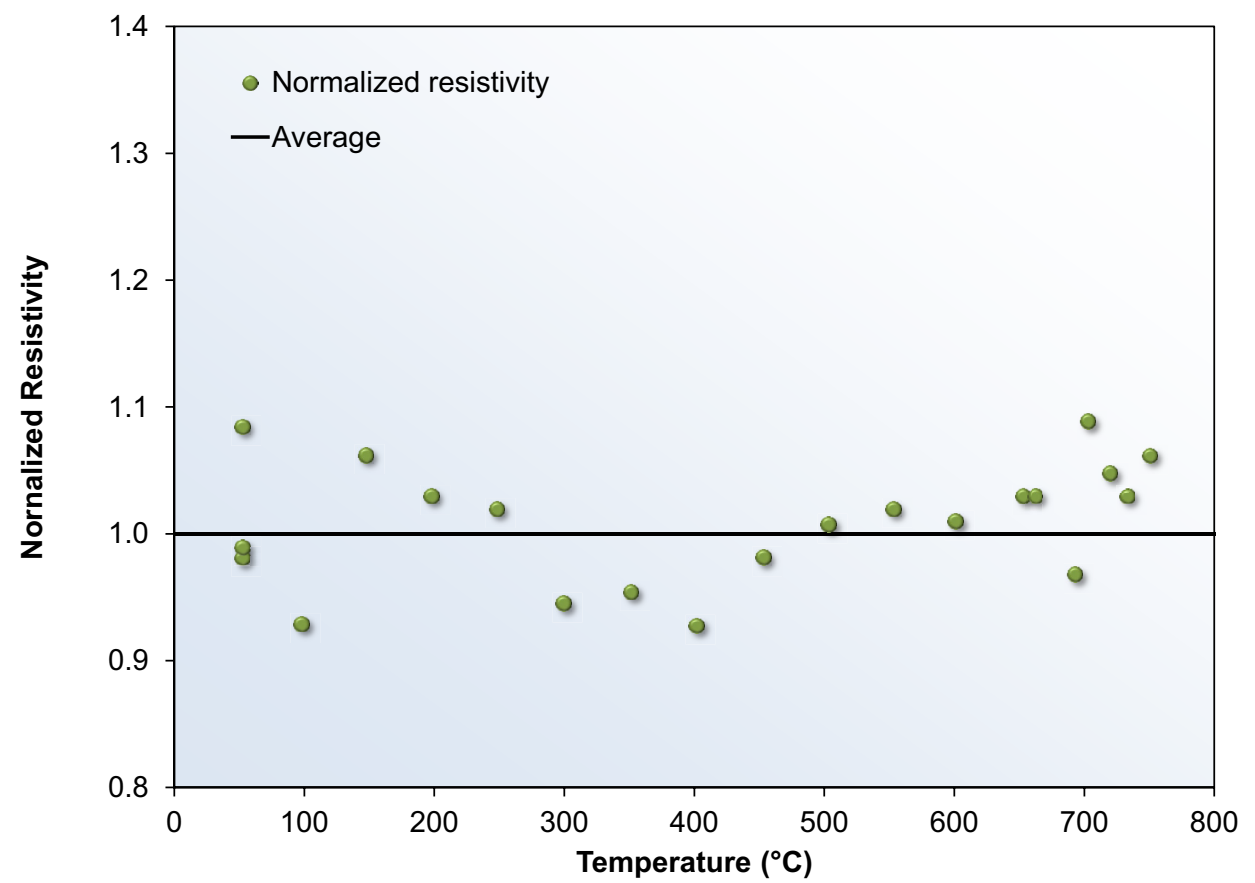

Figure 9. Resistivity data for KGT-1370 monitor.

Table 4. Summary of $\mathrm{SiC}$ evaluation results.

\begin{tabular}{|c|c|c|c|}
\hline Monitor & $\begin{array}{c}\text { Inferred Peak } \\
\text { Temperature }\left({ }^{\circ} \mathrm{C}\right)\end{array}$ & Dose (dpa) & $\begin{array}{c}\text { Predicted Test } \\
\text { Temperature }\left({ }^{\circ} \mathrm{C}\right)\end{array}$ \\
\hline KGT-1368 & Indeterminate & 0.1 & 110 \\
\hline KGT-1370 & Indeterminate & 0.1 & 725 \\
\hline
\end{tabular}

\section{Conclusions}

SiC monitors were used in selected positions during the ATR NSUF Drexel University Project 31091 irradiation as a way to determine peak irradiation temperatures reached during the test. Two of the $\mathrm{SiC}$ monitors that were used (KGT-1368 and KGT-1370) were evaluated to infer those temperatures. However, peak irradiation temperatures inferred from evaluation of the $\mathrm{SiC}$ monitors were indeterminate. A primary factor contributing to the poor performance of theses $\mathrm{SiC}$ monitors is believed to be the fact that the $\mathrm{SiC}$ monitors were used outside the recommended temperature and dose ranges. Based on these results, it therefore appears that $\mathrm{SiC}$ monitors cannot be reliably used outside of recommended temperature and dose ranges.

\section{References}

1. J. Gan, "Project 31091- Irradiation Test Plan for the ATR National Scientific User Facility - University of Illinois Project," PLN-3493, October 20, 2010.

2. W. F. Jones, "Thermal Analysis - ATR NSUF Drexel University HSIS Experiment," Project 31091, ECAR-1292, March 29, 2011. 
3. J. R. Mitchell, "ATR Neutronics Evaluation for the Drexel University Experiment in the HSIS," Project 31091, ECAR-1304, May 11, 2011.

4. D. L. Knudson, "Melt Temperatures for the Zr Growth Experiment Melt Wires," TEV-1007, September 2010.

5. K. L. Davis and D. L. Knudson, "Specimen Melt Temperatures for Use in the Advanced Test Reactor," TEV-1175, March 2011.

6. K.L. Davis, “Melt Wire Testing,” INL Interoffice Memorandum, October 14, 2011.

7. K. L. Davis, D.L. Knudson, J.E. Daw, J.L.Rempe and A.J. Palmer, "Melt Wire Sensors Available to Determine Peak Temperatures in ATR Irradiation Testing," 8th International Topical Meeting on Nuclear Plant Instrumentation, Control, and Human Machine Interface Technologies (NPIC\&HMIT 2012), San Diego, CA, July 22-26, 2012.

8. J. L. Rempe, K.G. Condie, Darrell Knudson, and L. L. Snead, Silicon Carbide Temperature Monitor Measurements at the High Temperature Test Laboratory, INL/EXT-10-17608, January 2010.

9. P. E. Murray, "Thermal Analysis of Irradiation Experiments in the ATR", Test Research and Training Reactors (TRTR) Annual Meeting, San Diego, CA, September 2012.

10. L. L. Snead, A. M. Williams, A. L. Qualls, "Revisiting the use of SiC as a Post Irradiation Temperature Monitor", Effects of Radiation on Materials, ASTM STP 1447, M. L. Grossbeck, Ed, ASTM International, West Conshohocken, PA, 2003. 